\title{
Liberary Mathematics of the Oulipo
}

\author{
Author Łukasz Matuszyk ${ }^{1}$ \\ ${ }^{1}$ University of Silesia in Katowice
}

\begin{abstract}
The paper focuses on the artistic phenomenon called liberature, in the context of its mathematical qualities and formulas used to create a work. In this literary type which inextricably connects the textual and the physical layer of the work, each element is expected to be created according to a certain formula which, in turn, should make up a holistic piece of literature. Artistic pieces similar to liberature in this aspect have existed for several thousand years, and nowadays researchers tend to call most of them proto-liberary. However, some of the works of the French literary group Oulipo are strictly liberary, in ways which will be indicated. In the article, I base on the theoretical idea behind liberature when discussing several pieces of the Oulipo, including Raymond Queneau's Cent mille milliards de poèmes (1961) and Georges Perec's Life A User's Manual (1978). The works will be analysed from the perspective of the theory of liberature, which began in 1999 with Zenon Fajfer's article "Liberature: Appendix to a Dictionary of Literary Terms."
\end{abstract}

Keywords: liberature, mathematics, the Oulipo, game in literature

\section{Introduction}

On November 24, 1960, the Oulipo group (also spelled OuLiPo, or OU-LI-PO, as stemming from Ouvroir de littérature potentielle, or workshop of potential literature) was founded by the writer Raymond Queneau and mathematician François Le Lionnais. Stemming from the inadequacies that they found in typical literature, their primary and overarching idea was to combine literature with mathematics, especially such branches of the latter as combinatorics and game theory. In the first manifesto of the group (which still had an unspecified name back then), Le Lionnais points to the exploration of various disciplines that literature might undertake and benefit from, and underlines the possibilities that the so-called exact sciences could offer literature:

\begin{abstract}
Mathematics - particularly the abstract structures of contemporary mathematics - proposes thousands of possibilities for exploration, both algebraically (recourse to new laws of composition) and topologically (considerations of textual contiguity, openness and closure). We're also thinking of anaglyphic poems, texts that are transformable by projection, etc. Other forays may be imagined, notably into the area of special vocabulary (crows, foxes, dolphins; Algol computer language, etc.). It would take a long article to enumerate the possibilities now foreseen (and in certain cases already sketched out). ${ }^{1}$
\end{abstract}

The programme of the Oulipo proposes a strong connection of literature with mathematics, one that would also make use of the ongoing advancements in mathematics and newest technologies, including computer languages. Le Lionnais also points to other possibilities which may be used by literary authors, such as specialist vocabulary from various scientific disciplines, e.g., zoology. The relevance of the disciplines used by the Oulipians, especially focused on the so-called exact sciences, is highlighted by Warren Motte, who claims that "[i]f the Oulipo insists upon combinatorics in its poetics, it is perhaps because combinatorics, whose status as a mathematical discipline is now established, is demonstrably functional in many literary structures, even some of the most traditional ones. That is, combinatorics offers a privileged locus for the interplay of mathematics and

${ }^{1}$ F. Le Lionnais, "Lipo: First Manifesto," in Oulipo: A Primer for Potential Literature, W. F. Motte, Trans. and Ed. (Normal, IL: Dalkey Archives Press, 1998), p. 27. 
literature." ${ }^{2}$ Further technological advancements, particularly the development of computers and their software, have been bringing new possibilities for the authors from the Oulipo group in more recent years.

\title{
2. Game in the Oulipo
}

At first sight, the game-like aspect of the group's programme might be difficult to notice, but it can be discernible in the constraint that the group enforces on the author, a quality strongly connected with the very idea of employing a mathematical quality in the literary creation. Since it is combined with a constraint, the game-like quality of the group's literary production does not mean that their works lack in discipline; per contra, for the Oulipo, "[c]onstraint is . . a commodious way of passing from language to writing. If one grants that all writing - in the sense both of the act of writing and of the product of that act - has its autonomy, its coherence, it must be admitted that writing under constraint is superior to other forms insofar as it freely furnishes its own code." Writing under constraint is expressly against the view of literary creation as contingent. The idea of a "workshop" rather points to the view of a literary work as a conscious process for both the author and the reader, an activity requiring effort. Peter Consenstein points to the constraint, which is one of the principal elements of the Oulipo's creative production, viewed as a very “conscious" process:

\begin{abstract}
Their "raison d'être" is the invention and application of literary constraints. The "artificial" nature of their contribution to "l'activité littérarie" refers to the relationship between mathematics and literary structures. Such a relationship necessitates an abstract and well-tuned consciousness of literature, one that depends on past knowledge. By "working under constraint" they have raised their level of consciousness because - their dictum - if an author does not define his or her constraint, the constraint will in turn define their work for them. In other words, all literature is built upon constraints, either consciously or unconsciously. Building consciousness through the use of constraints is the group Oulipo's greatest achievement. ${ }^{4}$
\end{abstract}

One might, then, summarize the general idea behind the Oulipo as being against the stream-of-consciousness or "inspirational" style of writing, as well as being mathematically-oriented and based on the principle that the author should carefully plan all the elements of her work before the process of artistic creation, just as a researcher in exact sciences first finds data and organizes them, and only then does he start analysing the results of his findings. This approach to the artistic production is by no means a new trend in literature, but it has been brought by the Oulipo to a particularly high level of complexity. Certainly, the mathematical structures employed in the works of the group are different from those presented in Dante Alighieri's Divine Comedy or earlier magic squares and Rabanus Maurus Magnentius' Liber de laudibus sanctae cruces from the $9^{\text {th }}$ century. Le Lionnais asserts that there are two main tendencies in the artistic production of the Oulipo: analytically- and synthetically-oriented. The analytic tendency is focused on works from the past and analyzes the possibilities which were not found by their authors, while the tendency towards a synthesis "is more ambitious: it constitutes the essential vocation of the Oulipo. It's a question of developing new possibilities unknown to our predecessors. This is the case, for example, of the Cent Mille Milliards de Poèmes or the Boolian haikus." It must be added that according to the Oulipo group, the rule, or limitation, is what allows a literary author to be creative. Therefore, their artistic production might tentatively be called a "literary mathematics." Referring mainly to the work of the Oulipo, Consenstein claims that "[i]t is only through a heightened sense of literary consciousness that any possibility of transformation, be it linguistic or personal, exists. By becoming conscious of the mathematical underpinnings of literary genres, the possibilities of innovation are endless; one's personal possibilities are endless."

\footnotetext{
${ }^{2}$ W. F. Motte, "Introduction" to Oulipo: A Primer for Potential Literature, W. F. Motte, Trans. and Ed. (Normal, IL: Dalkey Archives Press, 1998), p. 17.

${ }^{3}$ M. Bénabou, "Rule and Constraint," in Oulipo: A Primer for Potential Literature, W. F. Motte, Trans. and Ed. (Normal, IL: Dalkey Archives Press, 1998), p. 41.

${ }_{5}^{4}$ P. Consenstein, Literary Memory, Consciousness, and the Group Oulipo (Amsterdam, New York: Rodopi, 2002 ), pp. $16-17$.

${ }^{5}$ Le Lionnais, "Lipo: First Manifesto," p. 27.

${ }^{6}$ Consenstein, Literary Memory, Consciousness, and the Group Oulipo, pp. 22-23.
} 


\section{Mathematical game in Cent mille milliards de poèmes}

A realization of the principal ideas of the Oulipo is especially well-visible in the first works of the group. The work of Raymond Queneau entitled Cent mille milliards de poèmes (One Hundred Thousand Billion Poems) was presented to the public in 1961. This untypical poem - though focal for the Oulipo group and included by Le Lionnais in the "synthetic tendency" of the group's work - is a literary game with an essential mathematical quality. It consists of ten sonnets in which each one of the fourteen verses has ten possible combinations. Thanks to similar rhymes at the end of every combination, it is possible to build 100,000,000,000,000 (i.e., one hundred thousand billion, or 10 to the $14^{\text {th }}$ power ${ }^{7}$ ) proper sonnets.

Le Lionnais writes about Queneau's poem that "[t]hanks to this technical superiority, the work you are holding in your hands represents, itself alone, a quantity of text far greater than everything man has written since the invention of writing, including popular novels, business letters, diplomatic correspondence, private mail, rough drafts thrown into the wastebasket and graffiti." indeed wrote this inconceivable amount of text, or whether he rather acted as a literary "architect" who designed, with the use of mathematics, the multiple possibilities of reading, but the number of textual combinations is overwhelming. Although this huge number of sonnets contained in one rather physically thin volume is not unlimited either - just as the reading possibilities of Cortázar's Hopscotch or Johnson's The Unfortunates are not limitless - still, reading all of the combinations is unattainable for a human being. Even though the concept is based on simple combinatorics, the staggering number resulting from the use of such a mathematical strategy may be an astonishing realization for a person unversed in mathematics, since at first sight it might appear selfexplanatory to the reader that one can read all of the combinations.

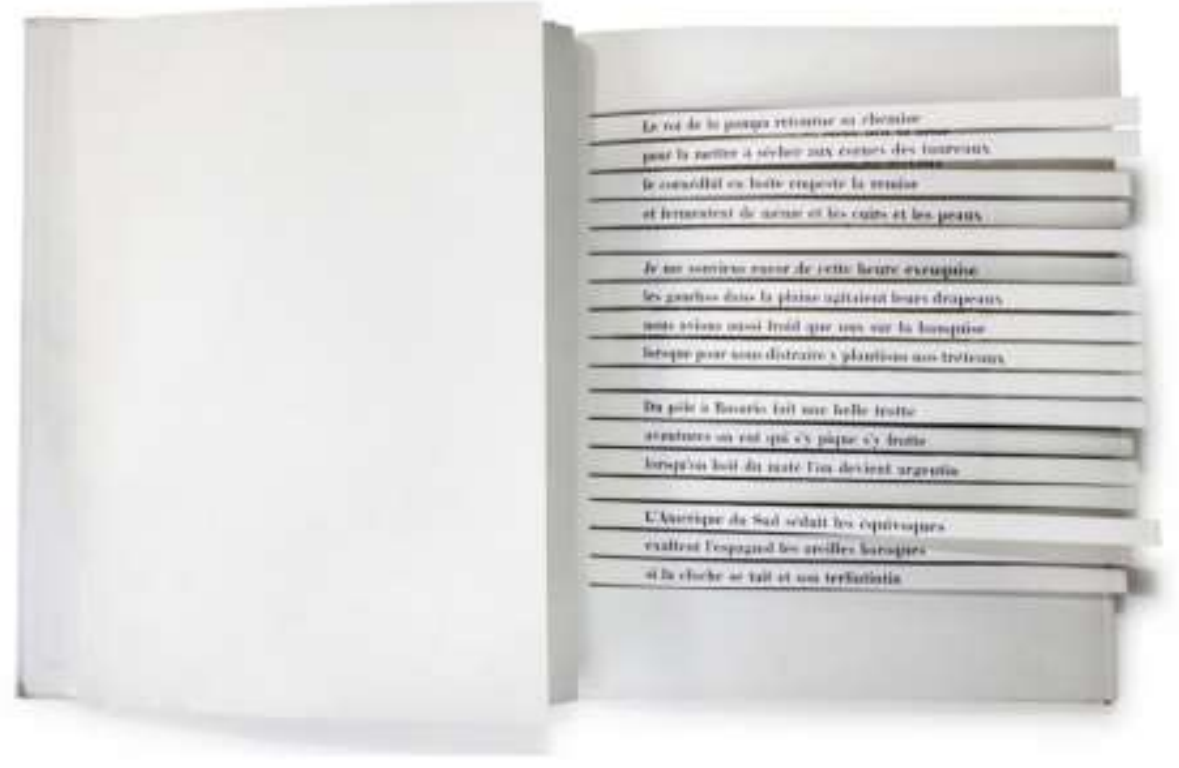

Fig. 1. Raymond Queneau, Cent mille milliards de poèmes $(1961)^{9}$

Zenon Fajfer, the Polish liberary author and theoretician of liberature, indicates that this piece is a representative of liberature, since the author planned the entire shape of the work in its various aspects, and in order to publish it, he had to act against numerous rules (mainly editorial) established by tradition, in order to

\footnotetext{
${ }^{7}$ In fact, the number of sonnets is smaller: since all combinations of $N$ elements, where any element appears once at a maximum in any given combination, gives $2^{N}-1$ combinations, then ten 14 -line poems can give $10^{14}-1$ separate combinations, which in total amounts to one sonnet less than the number above.

${ }^{8}$ After: Motte, "Introduction" to Oulipo: A Primer for Potential Literature, p. 3.

${ }^{9}$ From: http://highlike.org/raymond-queneau/ (6 Feb. 2016).
} 
create a textual work which is inconvenient to read because of its unwieldy format. Such a holistic work which is made into an object of visual appreciation may be included in the category of liberature, also called "total literature." ${ }^{10}$ Besides, Fajfer claims that Queneau had to be very conscious in the process of creating this multidimensional book: "In order to achieve the desired effect he [Queneau] had to break a very strong editorial taboo that forbids 'serious' literature for adults to depart from the time-honoured codex-form of the book, imposed by historical, technological and economic reality, due to which he managed to create one of the most original works of liberature."11 The view of Marcel Bénabou justifies such a judgment:

... it is actually in the passage from the rule to the constraint that the stumbling block appears: people accept the rule, they tolerate technique, but they refuse constraint. Precisely because it seems like an unnecessary rule, a superfluous redoubling of the exigencies of technique, and consequently no longer belongs - so the argument goes - to the admitted norm but rather to the process, and thus is exaggerative and excessive. It is as if there were a hermetic boundary between two domains: the one wherein the observance of rules is a natural fact, and the one wherein the excess of rules is perceived as shameful artifice. ${ }^{12}$

Such an attitude towards his own work might have been destructive for its author, but Queneau decided to participate in a "game" with the editorial tradition in order to create a work which is game-like for the reader as well. Even though this very attitude might have been serious - with the aim of enlarging the realm of literary creativity - there was also a danger that Queneau's extraordinary work, when viewed out of the context of the Oulipo's artistic ideas, would be considered an infantile attempt to become a controversial writer, or that the piece would be regarded as a book for children. It might not be claimed, however, that this piece has been created without meticulousness in combining the formal and the textual side. In fact, the technical side of the work has an inseparable connection with its semantics; as Warren Motte claims, the new, combinatory poetic form, "given its basis material, the individual precombinatory sonnet, erects a whole system of meta constraints: if the traditional metrics remain essentially intact (the combinatory integer being the alexandrine), the rhyme scheme and the syntactic and semantic structures must, on the contrary, bow to the new formal rules imposed by the combinatory ensemble. Each line of the ten master sonnets must be capable of being coherently integrated into a quasi-infinity of derived sonnets." ${ }^{\prime 13}$ The content is carved in the form, and the form is always chosen whether accidentally or consciously - by the reader.

This game-like aspect makes the literary production of the Oulipo a step on the development of liberature which as yet has its final point in e-liberature. Certainly, part of the author's choice is given to the reader, even though the latter can only choose from a limited (though very large) number of possibilities, and his choices may never be entirely informed, since accident plays an essential part in this game of reading. This almost-infinite limitation of the reader, however, may possibly yield a literally infinite number of workable interpretations, making Queneau's piece an open work, “a continuous potentiality of 'openness' - in other words, an indefinite reserve of meanings."14

\section{Architectural game-like structure of Life A User's Manual}

Other works of the Oulipo group contribute to the idea of approaching a literary work in a manner similar to playing a game, both in the process of designing and creating the piece and in the multi-layered process of reading. The second of the Oulipo's works worth mentioning in the present context is Georges Perec's Life A User's Manual (Fr. La Vie mode d'emploi 1978, first translated into English in 1987). The very title of this piece is reminiscent of a very practical type of publication: an instruction of how to make use of something - in this

\footnotetext{
${ }^{10}$ Z. Fajfer, "Liberature: Appendix to a Dictionary of Literary Terms," in: Liberature or Total Literature, K. Bazarnik, Trans. and Ed. (Kraków: Korporacja Ha!art, 2010), p. 23.

${ }^{11}$ Z. Fajfer, "From Combinatorics to Liberature: On Misunderstandings Connected with So-Called 'Experimental Literature'," in: Liberature or Total Literature, K. Bazarnik, Trans. and Ed (Kraków: Korporacja Ha!art, 2010), p. 131.

12 Bénabou, "Rule and Constraint," p. 41.

${ }^{13}$ Motte, "Introduction" to Oulipo: A Primer for Potential Literature, p. 4.

${ }^{14}$ U. Eco, The Open Work, Anna Cancogni, Trans. (Cambridge, MA: Harvard University Press, 1989), p. 10.
} 
case, of life, unless the title is interpreted as a statement that life is a user's manual. The form of the piece also alludes to the idea of an encyclopedia, which makes it similar to works such as Dante's The Divine Comedy. Perec's work, based on specific constraints just as any work of the Oulipo group, is built on the idea of literary architecture. The piece presents a fictitious ten-story building in a (non-existing) street in Paris, the inspiration for the work being Saul Steinberg's drawing The Art of Living (from 1949), which may help understand the structure of Perec's work.

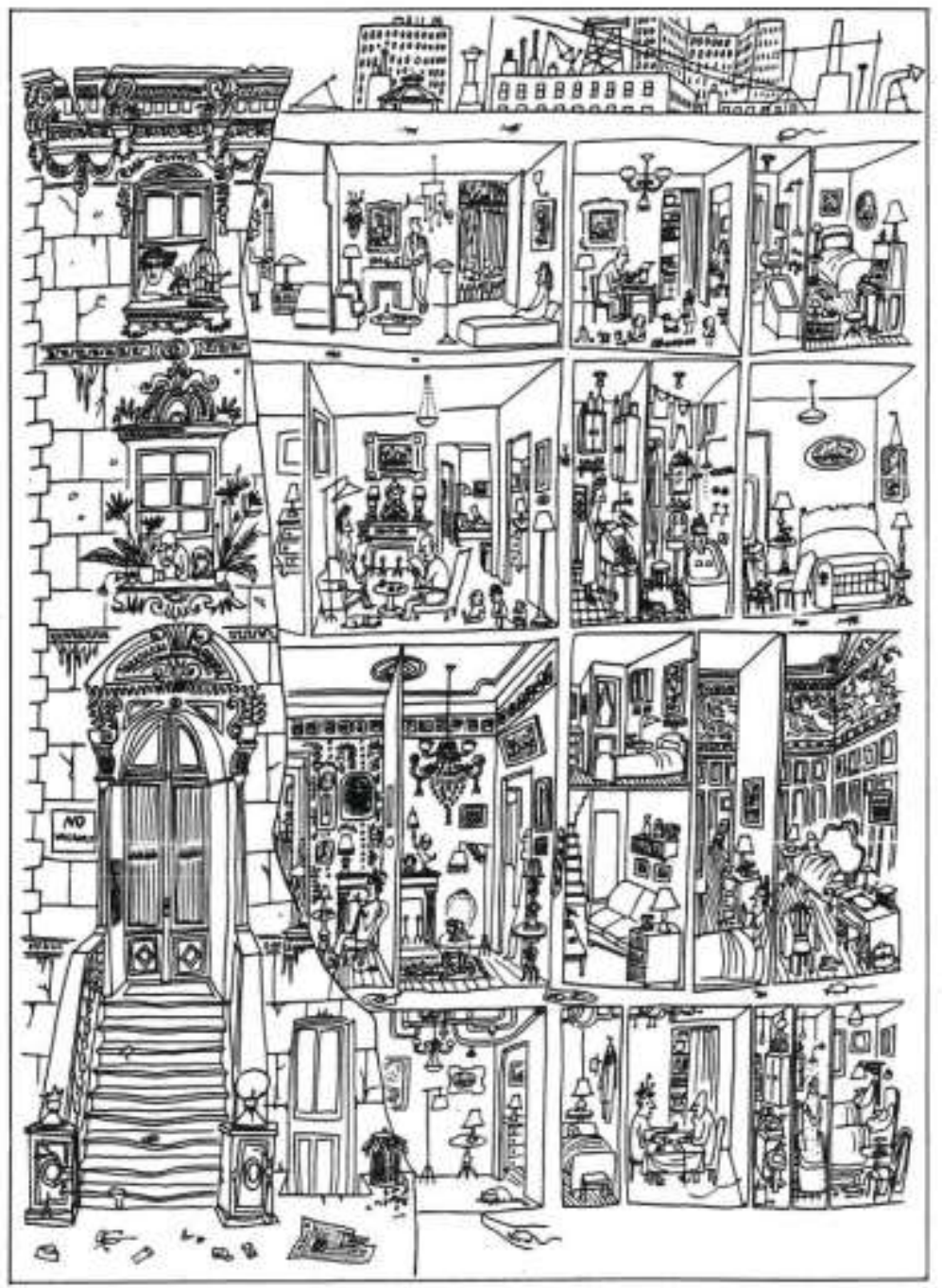

Figure 2. Saul Steinberg, The Art of Living (1949) ${ }^{15}$

An essential characteristic of the works of the Oulipo is the holistic structure of a literary artefact. Before he started writing Life A User's Manual, Perec had devoted several years to devise its rules, and these have been published in 1993 as Cahier des charges [a list of duties]. His detailed planning of the structure of his work is one of the elements contributing to its liberary quality. Life A User's Manual consists of six parts, divided into 99 chapters, an introduction and an epilogue. The piece should have one more chapter, since there are 10x10 fields in the plan of the apartment, but chapter 66 was deleted; in the plot, a picture of a girl taking a bite out of a biscuit is presented as a justification of this deletion, since, apparently, the whole plan was supposed to resemble a biscuit. The work includes interconnected stories (hence the subtitle "novels," in plural) of the Parisian apartment block's inhabitants. The main thread of the plot is the story of Percival Bartlebooth, but it is

${ }^{15}$ From: http://blogs.cornell.edu/exlibris/files/2014/05/Steinberg-Art-of-Living-apt.-1bpr8nq.jpg (18 Mar. 2016). 
interlinked with many other threads, including the stories of other inhabitants of the block - both present and past - and other people in the lives of the inhabitants. At the beginning of the narrative, the apartment is presented at one second, before 8 p.m. on June 23, 1975, a while after Bartlebooth's death.

Paul A. Harris identifies Life A User's Manual as a game not only for the reader, but also for the author; Harris claims that " $[\mathrm{t}]$ he formal underpinnings of Perec's novel took shape as an elaborate puzzle he had to complete, and this sense of gamesmanship and ludic pleasure passes into the hands of a reader who tries to decode and reassemble the textual puzzle. . . . Perec's text is recursive in a specific Oulipian sense; it inscribes its own processes of production into its images, themes, and content, and also implicates readers in a potentially endless self-referential game of solving the textual puzzle." 16 The work employs the idea of arranging a jigsaw puzzle in two aspects. Firstly, it is connected with the plot, since Bartlebooth's paintings are turned into a jigsaw puzzle by Gaspard Winckler. More importantly in the context of a discussion of liberature is the formal aspect: the work is constructed to form a jigsaw puzzle itself, and to arrange it, the reader needs to know the literary texts, places, persons and other elements contained in the index (of 5000 entries) at the end of the work. If the reader is willing to play this game, she will be able to make up complete stories out of the fragmentary narratives presented in the first layer of the text.

There is also a strictly mathematical aspect functioning as one of the constructive principles of Life A User's Manual. The mathematical form used in Perec's work is the so-called Graeco-Latin square, which might be represented by means of letters and digits. In every row and in every column, each letter and each digit should be used exactly once.

\begin{tabular}{|l|l|l|l|l|}
\hline A1 & B2 & C3 & D4 & E5 \\
\hline C2 & D3 & E4 & A5 & B1 \\
\hline E3 & A4 & B5 & C1 & D2 \\
\hline B4 & C5 & D1 & E2 & A3 \\
\hline D5 & E1 & A2 & B3 & C4 \\
\hline
\end{tabular}

Fig. 3. An example of a Graeco-Latin square ${ }^{17}$

In Perec's work, there are two lists of words divided into categories (40 categories in total, such as "walls" and "floor," each with 10 elements) and two lists of novelists and words from the titles of famous works, which are considered in pairs (such as Racine-Shakespeare, Pride-Prejudice, Crime-Punishment), and from which according to the Cahier des charges - a fragment with the use of the word from a particular category or a literary quote is required in every chapter. Each pair is governed by one cell of the square's array, so that every combination of elements may be found in the whole piece. More specifically, Life A User's Manual should contain every one of the 10 elements from the first category (such as "walls") combined with each of the 10 elements of the second one (e.g., "floor").

Another mathematical problem on which Life A User's Manual is based, contributing to the game-like value and close to the field of computer science, is the second constructive principle of the work: the so-called knight's tour problem. As a task connected with a game of chess, it consists in finding a way in which the knight (which can move only diagonally) moves through the chessboard in such a way that it visits every square exactly once. As it has been pointed out, the plan of Perec's work is made on 100 fields - 10 floors of 10 elements each -

\footnotetext{
${ }^{16}$ P. A. Harris, “The Invention of Forms: Perec's Life A User's Manual and a Virtual Sense of the Real," SubStance, vol. 23, No. 2 (1994), p. 58.

${ }^{17}$ From: http://www.itl.nist.gov/div898/handbook/pri/section3/pri3322.htm (19 Mar. 2016).
} 
which makes it structurally similar to a chessboard, although slightly bigger. The idea realized in Life A User's Manual is to devote every chapter to one of those elements on the "chessboard." In every chapter, there is a numerical reference to the position of this particular chapter (the Y-axis and the X-axis, respectively) on the 100field chessboard. This characteristic of the work points to its liberariness not only by its "gameplay," but also by the holistic structure: the overarching idea of a work as a game of chess is reflected in its individual chapters, and thus the chapters are formally connected with one another, apart from being connected by other elements, such as the invariable place and the main theme.

Perec's novel may also be indicated as an example of a work presenting "hyperreality," or, in other words, a literary piece which becomes reality. As Harris points out, "The puzzling way in which this book founded on arbitrary constraints also fabricates the real is exemplary in an era characterized by, on the one hand, the receding of reality into algorithms or codes, and on the other, a resultant investment in or discourse about 'the real. $", 18$

\section{Conclusion}

As it has been pointed out, the most essential bases of the literary work of the Oulipo are the mathematical quality and the architectural structure of a work, and both of these are combined with a "bodily" aspect of such an artistic piece. In his book under an accurate title Words Made Flesh, Florian Cramer asserts that words of a language may themselves become a reality as soon as they are perceived as detached from their linguistic origin. Cramer refers to the Algol programming language, whose source code was not used to generate poetic works, but it "was the poem itself. Program code ceased to be seen merely as a 'transparent' technical tool detached from the perceived art work, but as an aesthetic object itself. For the first time, artistic programming was not a means to another end. Computer programming languages appealed to the Oulipo as yet another formal constraint... . A 'poor' language that limited a writer's freedom, Algol was yet another playground for Oulipo poets to overcome artificial constraints through imagination and cleverness." 19 A liberary quality to be found in this technique is, firstly, making poetry out of a practical, technical tool, and secondly, applying a set of formal rules and constraints in the game-like process of creating a literary work. It is not only in the works of the Oulipo, however, that these characteristics may be found.

\section{References}

[1] M. Bénabou, "Rule and Constraint," in Oulipo: A Primer for Potential Literature. W. F. Motte, Trans. and Ed. Normal, IL: Dalkey Archives Press, 1998, pp. 35-38.

[2] P. Consenstein, Literary Memory, Consciousness, and the Group Oulipo. Amsterdam, New York: Rodopi, 2002.

[3] F. Cramer, Words Made Flesh: Code, Culture, Imagination. Rotterdam: Piet Zwart Institute, 2005.

[4] U. Eco, The Open Work. Anna Cancogni, Trans. Cambridge, MA: Harvard University Press, 1989.

[5] Z. Fajfer, "Liberature: Appendix to a Dictionary of Literary Terms," in Liberature or Total Literature, K. Bazarnik, Trans. and Ed. Kraków: Korporacja Ha!art, 2010, pp. 22-28.

[6] Z. Fajfer, "From Combinatorics to Liberature: On Misunderstandings Connected with So-Called 'Experimental Literature,", in Liberature or Total Literature, K. Bazarnik, Trans. and Ed. Kraków: Korporacja Ha!art, 2010, pp. $127-132$.

[7] P. A. Harris, “The Invention of Forms: Perec's Life A User's Manual and a Virtual Sense of the Real," SubStance, vol. 23, pp. 56-85, No. 2 (1994).

[8] F. Le Lionnais, "Lipo: First Manifesto," in Oulipo: A Primer for Potential Literature, W. F. Motte., Trans. and Ed. Normal, IL: Dalkey Archives Press, 1998, pp. 26-28.

\footnotetext{
${ }^{18}$ Harris, "The Invention of Forms...", p. 56.

${ }^{19}$ F. Cramer, Words Made Flesh: Code, Culture, Imagination (Rotterdam: Piet Zwart Institute, 2005), p. 94.
} 
[9] W. F. Motte, "Introduction" to Oulipo: A Primer for Potential Literature. W. F. Motte, Trans. and Ed. Normal, IL: Dalkey Archives Press, 1998, pp. 1-22.

[10] http://blogs.cornell.edu/exlibris/files/2014/05/Steinberg-Art-of-Living-apt.-1bpr8nq.jpg (18 Mar. 2016).

[11] http://highlike.org/raymond-queneau/ (6 Feb. 2016).

[12] http://www.itl.nist.gov/div898/handbook/pri/section3/pri3322.htm (19 Mar. 2016). 